\title{
Indirect reduction of Ralstonia solanacearum via pathogen
} helper inhibition

\author{
Mei $\mathrm{Li}^{1,2}$, Thomas Pommier (D) ${ }^{3}$, Yue Yin ${ }^{1}$, Jianing Wang ${ }^{1}$, Shaohua Gu${ }^{4}$, Alexandre Jousset (iD) ${ }^{1}$, Joost Keuskamp (iD ${ }^{2,5}$, Honggui Wang ${ }^{6}$, \\ Zhong Wei (iD ${ }^{1 凶}$, Yangchun Xu (iD ${ }^{1}$, Qirong Shen ${ }^{1}$ and George A. Kowalchuk ${ }^{2}$
}

(c) The Author(s) 2021

The rhizosphere microbiome forms a first line of defense against soilborne pathogens. To date, most microbiome enhancement strategies have relied on bioaugmentation with antagonistic microorganisms that directly inhibit pathogens. Previous studies have shown that some root-associated bacteria are able to facilitate pathogen growth. We therefore hypothesized that inhibiting such pathogen helpers may help reduce pathogen densities. We examined tripartite interactions between a model pathogen, Ralstonia solanacearum, two model helper strains and a collection of 46 bacterial isolates recovered from the tomato rhizosphere. This system allowed us to examine the importance of direct (effects of rhizobacteria on pathogen growth) and indirect (effects of rhizobacteria on helper growth) pathways affecting pathogen growth. We found that the interaction between rhizosphere isolates and the helper strains was the major determinant of pathogen suppression both in vitro and in vivo. We therefore propose that controlling microbiome composition to prevent the growth of pathogen helpers may become part of sustainable strategies for pathogen control.

The ISME Journal (2022) 16:868-875; https://doi.org/10.1038/s41396-021-01126-2

\section{INTRODUCTION}

Plant pathogens have a large negative impact on agricultural production, and there is an urgent need for sustainable strategies to prevent diseases while reducing the environmental footprint of modern agriculture [1]. Plant root-associated microorganisms are increasingly studied in relation to their ability to help keep plants healthy $[2,3]$. However, while some microbiomes are better at preventing pathogen growth than others, it often remains unclear which interactions shape pathogen success. To date, most research has focused on pathogen inhibition by some specific plant-associated microorganisms. In line with this logic, most microbiome management strategies have been centered around bioaugmentation with microorganisms that can directly inhibit pathogen growth [4, 5]. These biopesticides represent a promising approach, but are often constrained by the low density that inoculated strains can reach in a multispecies microbiome and the context-dependent success of microbial introductions [6-8]. These shortcomings are at least partly due to inadequate consideration of the complex microbial interactions that impact pathogen inhibition or proliferation $[9,10]$.

We propose a new perspective in pathogen ecology by placing focus on microorganisms that promote pathogen growth. Recent studies have shown that a significant fraction of plant-associated microorganisms can promote pathogen growth and pathogenicity [11]. Facilitative microbe-microbe interactions are indeed widespread, and such interactions may emerge for instance as a result of cross- feeding [12] or production of public goods such as siderophores [13]. Facilitation has been recently highlighted as a potential determinant of pathogen success $[9,14]$. We therefore postulate that affecting naturally-occurring helper bacteria of pathogens may provide an alternative means of controlling pathogen development, as compared to the application of pesticides or biopesticides. To this end, we hypothesized that indirect effects via inhibition of pathogen helpers would have a significant impact on realized pathogen densities and subsequent disease incidence.

We first established the prevalence of pathogen-helper bacteria in the rhizosphere by screening a library of 640 rhizobacterial strains isolated from tomato rhizosphere soil. We specifically tested their pairwise interactions with Ralstonia solanacearum, the causative agent of bacterial wilt, a major disease affecting more than 200 crops at a global scale $[15,16]$. We observed that a significant fraction of all isolates promoted pathogen growth in vitro. We then selected two representative pathogen helper strains and built tripartite cultivation experiments in which the pathogen was grown together with one of the helper strains and the supernatants of 46 individual bacterial strains chosen to represent a gradient of positive, neutral or negative interactions with the pathogen. Pathogen growth was monitored in each community, both in vitro and in the tomato rhizosphere. We then expressed pathogen density and disease severity as a function of a direct (effect on pathogen) and indirect (effect on the helper

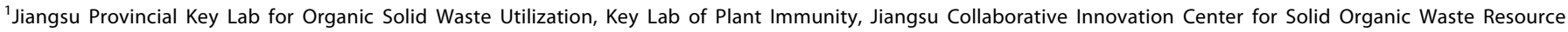

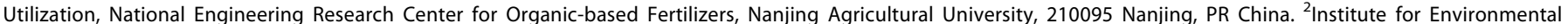

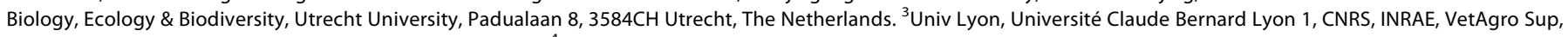

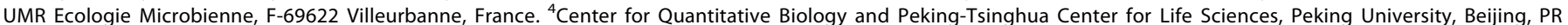

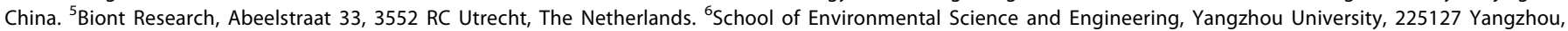
Jiangsu, PR China. ${ }^{凶}$ email: weizhong@njau.edu.cn
} 


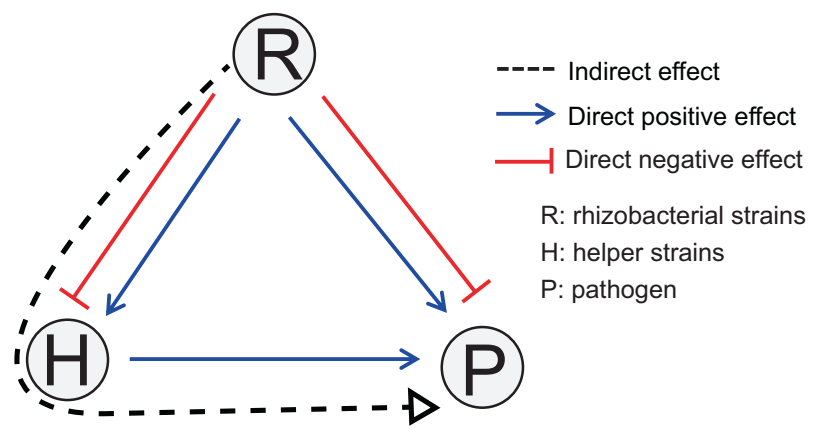

Fig. 1 Conceptual overview of direct and indirect effects of rhizobacterial strains on pathogen growth. In this work, we subdivided the net, apparent effect of single rhizosphere bacterial isolates (R) on pathogen density into direct effects on the pathogen $(\mathrm{P})$ and indirect effects mediated by interactions with helper bacteria $(\mathrm{H})$.

strain) pathways for each of these rhizobacteria (Fig. 1). Part of the resulting data was also used to model the relative importance of direct versus indirect effects in determining realized pathogen density and subsequent disease severity. Based upon the results of these experiments, we discuss the potential utility of bioaugmentation strategies that target pathogen helpers as an element of integrated pathogen control.

\section{MATERIALS AND METHODS Rhizosphere soil sampling}

A total of 20 rhizosphere soil samples (20 tomato plants) were collected at the flowering stage from a tomato field located in Qilin town, Jiangsu province, China, $118^{\circ} 57^{\prime} \mathrm{E}, 32^{\circ} 03^{\prime} \mathrm{N}$, which had been infested by the pathogen Ralstonia solanacearum for more than 15 years [8]. After uprooting plants, excess soil was first gently shaken from the roots, and the remaining soil attached to roots was considered as rhizosphere soil. Each rhizosphere soil sample was then used for bacterial strain isolation.

\section{Isolation and identification of rhizobacteria}

Isolation. A total of 640 bacterial strains were isolated from the fresh rhizosphere soil samples, according to a previously established protocol [11]. Briefly, $1 \mathrm{~g}$ of each rhizosphere sample was mixed with $9 \mathrm{~mL}$ MS buffer solution $\left(50 \mathrm{mM}\right.$ Tris- $\mathrm{HCl}[\mathrm{pH} 7.5], 100 \mathrm{mM} \mathrm{NaCl}, 10 \mathrm{mM} \mathrm{MgSO}_{4}, 0.01 \%$ gelatin) in a rotary shaker at $170 \mathrm{rpm} \mathrm{min}{ }^{-1}$ for $30 \mathrm{~min}$ at $30^{\circ} \mathrm{C}$. After serial dilution in MS buffer solution, 100- $\mu$ l volumes of the diluted soil suspensions were plated on $1 / 10$ tryptone soy agar (1/10 TSA, $1.5 \mathrm{~g} \mathrm{~L}^{-1}$ tryptone, $0.5 \mathrm{~g} \mathrm{~L}^{-1}$ soytone, $0.5 \mathrm{~g} \mathrm{~L}^{-1}$ sodium chloride, and $15 \mathrm{~g} \mathrm{~L}^{-1}$ agar, $\mathrm{pH}$ 7.0). After a $48-\mathrm{h}$ incubation at $30^{\circ} \mathrm{C}$ in the dark, 32 isolates were randomly picked per rhizosphere soil sample. To avoid potential fungal contamination, only highly diluted samples were used for isolation. The isolates were then re-streaked on TSA plates for colony purification. Approximately $5.5 \%$ (35 isolates) of the bacterial isolates failed to grow on the TSA plates for unknown reasons when we re-streaked them and were therefore omitted from the dataset. The final collection thus consisted of 605 bacterial isolates derived from 20 rhizosphere soil samples. All purified isolates were cultured in $100 \mu$ l tryptone soy broth (TSB, liquid TSA) in 96well microtiter plates at $30^{\circ} \mathrm{C}$ with shaking (rotary shaker at $170 \mathrm{rpm}$ ) for $18 \mathrm{~h}$ before freezing and storing at $-80^{\circ} \mathrm{C}$ in $15 \%$ glycerol.

Strain identification. We sequenced the full $16 \mathrm{~S}$ rRNA gene to taxonomically identify all 605 rhizobacterial isolates. The $16 \mathrm{~S}$ rRNA gene was sequenced via Sanger sequencing of PCR products from glycerol stocks by Shaihai Songon Biotechnology Co., Ltd, Shaihai Station. The PCR system $(25 \mu \mathrm{l})$ was composed of $1 \mu \mathrm{l}$ of bacterial cells (overnight culture), $12.5 \mu \mathrm{l}$ mixture, $1 \mu \mathrm{l}$ of forward (27 F: 5-AGA GTT TGA TCA TGG CTC AG-3) and reverse primer (1492 R: 5-TAC GGT TAC CTT GTT ACG ACT T-3) each [17] and $9.5 \mu \mathrm{l}$ of sterilized water. PCR was performed by initially denaturizing at $95^{\circ} \mathrm{C}$ for $5 \mathrm{~min}$, cycling 30 times with a 30-s denaturizing step at $94^{\circ} \mathrm{C}$, annealing at $58^{\circ} \mathrm{C}$ for $30 \mathrm{~s}$, extension at $72^{\circ} \mathrm{C}$ for $1 \mathrm{~min} 30 \mathrm{~s}$, and a final extension at $72^{\circ} \mathrm{C}$ for $10 \mathrm{~min}$. The $16 \mathrm{~S}$ rRNA gene sequences were identified using $\mathrm{NCBI}$ databases and homologous sequence similarity. A total of 90 bacterial isolates that were identified as Ralstonia solanacearum were removed from further analyses, resulting in $\mathbf{5 1 5}$ remaining isolates.

\section{Direct effect of rhizobacteria on pathogen growth in vitro}

We used $R$. solanacearum strain QL-Rs1115 tagged with the pYC12mCherry plasmid as a model bacterial pathogen $[8,18]$. We first tested the direct effects of the 515 non- $R$. solanacearum bacterial strains on the growth of $R$. solanacearum in vitro by using supernatant assays. Briefly, after $48 \mathrm{~h}$ of growth in NB (nutrient broth) medium (glucose $10.0 \mathrm{gl}^{-1}$, tryptone $5.0 \mathrm{gl}^{-1}$, yeast extract $0.5 \mathrm{gl}^{-1}$, beef extract $3.0 \mathrm{gl}^{-1}, \mathrm{pH} 7.0$ ) on a shaker at $170 \mathrm{rpm}, 30^{\circ} \mathrm{C}$, all bacterial cultures were filter sterilized to remove living cells $(0.22 \mu \mathrm{m}$ filter). Subsequently, $20 \mu \mathrm{l}$ of sterile supernatant from each strain's culture and $2 \mu \mathrm{l}$ overnight culture of the pathogen (adjusted to $\mathrm{OD} 600=0.5$ after $12 \mathrm{~h}$ growth at $30^{\circ} \mathrm{C}$ with shaking) were added into $180 \mu \mathrm{l}$ of fresh NB medium (5-times diluted, in order to better reflect the effect of the supernatant). Control treatments were inoculated with $20 \mu \mathrm{l}$ of $5 \mathrm{X}$ diluted NB media instead of the bacterial supernatant. Each treatment was conducted in triplicate. All bacterial cultures were grown for $48 \mathrm{~h}$ at $30^{\circ} \mathrm{C}$ with shaking $(170 \mathrm{rpm})$ before measuring pathogen density as red mCherry protein fluorescence intensity (excitation: $587 \mathrm{~nm}$, emission: $610 \mathrm{~nm})[9,11]$ which was linearly related to the CFU of pathogen $R$. solanacearum (Fig. S1). To test for significance of growth promotion or inhibition, $R$. solanacearum densities were $\log _{10^{-}}$ transformed prior to analyses of variance (ANOVA) and Bonferroni $t$ test to compare mean differences between each rhizobacterial supernatant treatment and the control treatment, with $p$ values less than 0.05 considered statistically significant. The effect on pathogen growth was defined as the percentage of improvement or reduction in pathogen growth by the supernatant compared to the control treatment. When the effect on pathogen growth was positive, i.e., when the supernatants from strains significantly promoted the growth of the pathogen, they were considered as helpers of the pathogen. If the effect on pathogen growth was negative, i.e., when the supernatants from strains significantly inhibited the growth of the pathogen, they were considered as inhibitors of the pathogen.

\section{Assessing strain redundancy among the 515 non-Ralstonia solanacearum bacteria}

We assessed possible redundancy among the 515 strains of the nonRalstonia solanacearum rhizobacteria. To encompass both taxonomic and functional redundancies, we considered the $16 \mathrm{~S}$ rRNA gene sequences as well as the direct effect of their supernatant on Ralstonia solanacearum. Self BLAST searches were performed on the full 515 sequence dataset using the makeblastdb and blastn commands from the BLAST command line tool [19]. Sequences showing $>99 \%$ identity over $>95 \%$ of the full length of the $16 \mathrm{~S}$ rRNA gene were considered as taxonomically redundant. We then compared the direct effects on pathogen growth of the taxonomically redundant strains, and removed those showing the same patterns of interactions (positive, negative or neutral). Accordingly, (see the dataset "Library of rhizobacterial strains" in the supplementary information), 355 of the 515 strains $(68.9 \%)$ were removed from the original dataset for further analyses.

\section{Phylogenetic tree construction}

The $16 \mathrm{~S}$ rRNA gene sequences of the 160 non-redundant bacteria were aligned using MUSCLE [20]. Sequences in the alignment were trimmed at both ends to obtain maximum overlap using the MEGA X software, which was also used to construct taxonomic cladograms [21]. We constructed a maximum-likelihood (ML) tree, using a General Time Reversible (GTR) + G + I model, which yielded the best fit to our data set. Bootstrapping was carried out with 100 replicates retaining gaps. A taxonomic cladogram was created using the EVOLVIEW web tool (https://evolgenius.info//evolview-v2/). To show the relationship between phylogeny and the effects of rhizobacteria on pathogen growth, we added taxonomic status (phylum) of each rhizobacterial strain and its effect on pathogen growth as heatmap rings to the outer circle of the tree separately (Fig. 2B).

\section{Effects of rhizobacteria on pathogen helper strains growth in vitro}

We then assessed the potential of different rhizosphere isolates to inhibit helper strains. We first selected two model helper strains (Phyllobacterium ifriqiyense LM1 (Pi) and Microbacterium paraoxydans LM2 (Mp)), which showed strong positive effects on pathogen growth both in co-culture and 

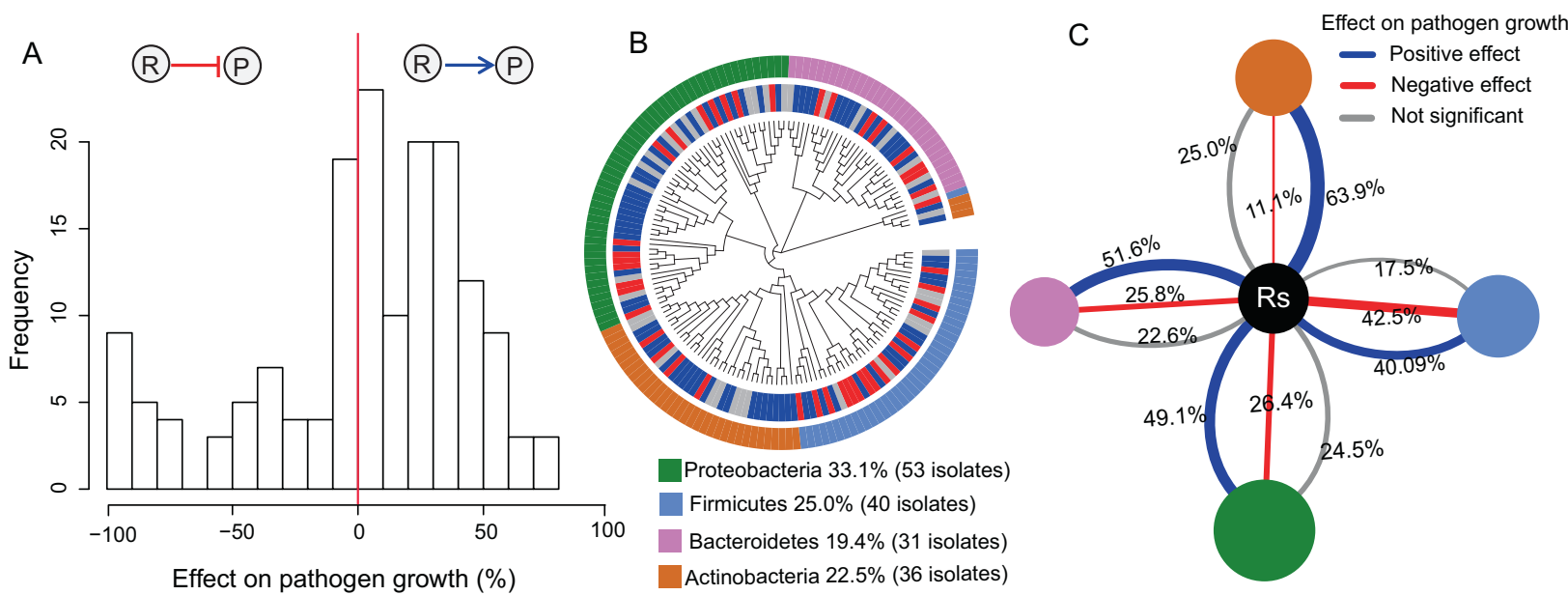

Fig. 2 Taxonomic characterization of rhizobacterial isolates that inhibited or helped the growth of Ralstonia solanacearum. A Distribution of in vitro effects of 160 rhizobacterial supernatants on $R$. solanacearum growth. The red vertical line represents no effect on $R$. solanacearum growth. B Cladogram depicting the phylogenetic relationship among the 160 isolates based on their full-length $16 \mathrm{~S}$ rRNA gene sequences. The inner ring depicts the different effect of isolates supernatant on $R$. solanacearum growth: positive effect (blue), negative effect (red) and no significant effect (gray). The outer ring shows the four phyla to which the isolates belong. $\mathbf{C}$ The proportion of rhizobacterial isolates per phylum whose supernatant showed inhibitory, stimulatory or no effect on $R$. solanacearum growth. The size of the circles represents the number of rhizobacterial isolates in the given phylum. The thickness of lines represents the percentage of rhizobacterial isolates that have the indicated effect on $R$. solanacearum growth in each phylum.

in supernatant assays (Fig. S2). We defined the effect of rhizobacterial strains on the growth of helpers as the indirect effect on $R$. solanacearum growth. To study these indirect effects, we first chose a subset of 46 rhizobacterial strains representing a gradient of positive, neutral or negative effect on pathogen growth based on supernatant assays (results in $x$ axis of Figs. $3 C$ and $4 A, B, C)$. We then tested the effects of these 46 rhizobacterial strains on the growth of each of the two helper strains using supernatant assays. Briefly, after $48 \mathrm{~h}$ growth in NB media, each of the 46 bacterial monocultures was passed through a $0.22 \mu \mathrm{m}$ filter to remove living cells. Then $20 \mu \mathrm{l}$ of sterile supernatant from each strain's culture and $2 \mu \mathrm{l}$ overnight culture of $\mathrm{Pi}$ or $\mathrm{Mp}$ (adjusted to $\mathrm{OD}_{600}=0.5$ after $12 \mathrm{~h}$ growth at $30^{\circ} \mathrm{C}$ with shaking) were added into $180 \mu$ l of fresh NB medium (5-times diluted, in order to better reflect the effect of the supernatant). Control treatments were inoculated with $20 \mu \mathrm{l}$ of $5 \times$ diluted NB media instead of a bacterial supernatant. Each treatment was replicated four times. All bacterial cultures were grown for $24 \mathrm{~h}$ at $30^{\circ} \mathrm{C}$ with shaking $(170$ $\mathrm{rpm}$ ) before measuring helper density as optical density $\left(\mathrm{OD}_{600}\right)$. To test for significance of growth promotion or inhibition, we used analyses of variance (ANOVA) and Bonferroni $t$ test to compare mean differences of helper density between each rhizobacterial supernatant treatment and the control treatment, with $p$ values lower than 0.05 being considered statistically significant. The effect of rhizobacteria on the helpers' growth (results in $y$ axis of Fig. $3 C$ and $x$ axis of Fig. 4D, E, F) was defined as the percentage of increase or reduction in helper growth by the supernatant compared to the control treatment.

\section{In vitro pathogen growth in the presence of a helper strain and supernatant from rhizobacterial isolates}

To disentangle the direct effects from the indirect effects of rhizobacteria on $R$. solanacearum growth, we compared their relative effects using in vitro triculture assays comprised of $R$. solanacearum, one of the two helper strains and supernatant of one of the 46 chosen rhizobacterial strains. Briefly, after $48 \mathrm{~h}$ of growth in NB media, each of the 46 bacterial monocultures was passed through a $0.22 \mu \mathrm{m}$ filter to remove living cells. Then, $20 \mu \mathrm{l}$ of sterile supernatant from each strain's culture and $2 \mu \mathrm{l}$ overnight culture of $\mathrm{Pi}$ or $\mathrm{Mp}$ (densities were adjusted to $\sim 10^{7}$ cells per $\mathrm{ml}$ ) were added to $180 \mu \mathrm{l}$ of fresh NB medium (5-times diluted). Each treatment was replicated four times. At the same time, $2 \mu \mathrm{l}$ overnight culture of mCherry-tagged $R$. solanacearum (density was adjusted to $\sim 10^{6}$ cells per $\mathrm{ml}$ ) was added to each treatment in 96-well plates at $30^{\circ} \mathrm{C}$ with shaking $(170 \mathrm{rpm})$. After 24 -h growth, $R$. solanacearum density (results in y axis of Fig. 4A, D) was measured as the red mCherry protein fluorescence intensity (excitation: $587 \mathrm{~nm}$, emission: $610 \mathrm{~nm}$ ) with a SpectraMax M5 plate reader.
In vivo pathogen growth and plant disease development in the presence of a helper strain and a rhizobacterial strain

To validate in vitro results, we set up greenhouse experiments where plants were inoculated with a bacterial consortium consisting of $R$. solanacearum, one of the two helper strains and a test rhizobacterial strain. Tomato seeds (Lycopersicon esculentum, cultivar "Ai hong sheng") were surface-sterilized by soaking them in $3 \% \mathrm{NaClO}$ for $5 \mathrm{~min}$ and in $70 \%$ ethyl alcohol for $1 \mathrm{~min}$ before being germinated on water-agar plates for 2 days. Seeds were then sown into seedling trays containing gamma irradiation-sterilized (to avoid potential effects of the resident community) seedling substrate (Huainong, Huaian Soil and Fertilizer Institute). At the three-leaf stage, tomato plants were transplanted to seedling trays containing $200 \mathrm{~g}$ of the same seedling substrate as describe above.

To relate our results to practical application conditions, we selected a subset of 12 strains that displayed a range of inhibitions effects on pathogen and helpers (Table S1) out of the 46 rhizobacterial isolates used for the in vitro assays. Each rhizobacterial strain was used in combination with each of the two helper strains and $R$. solanacearum, resulting in a total of 28 treatments (Table S2), including a water control, $R$. solanacearum alone, and $R$. solanacearum with just each of the two helper strains (results in Fig. 3B, C). For each treatment, four replicate seedling trays were used, with each replicate seedling tray containing 4 tomato plants. Three days after transplantation, plants of each treatment were inoculated with one of the two helper strains, alone or in combination with one of the rhizobacterial strains, using the root drenching method at a final concentration of $10^{8} \mathrm{CFU} \mathrm{g}{ }^{-1}$ soil for each bacterial strain [22]. Seven days after inoculation of helper alone or together with rhizobacteria, $R$. solanacearum was introduced to the roots of all plants at a final concentration of $10^{7} \mathrm{CFU} \mathrm{g}{ }^{-1}$ soil. The positive control treatment with $R$. solanacearum alone was inoculated only with the pathogen, and the negative control treatment was not inoculated with any bacteria. Tomato plants were maintained under standard greenhouse conditions (i.e., at natural temperature variation ranging from $28^{\circ} \mathrm{C}$ to $32^{\circ} \mathrm{C}, 15 / 9 \mathrm{~h}$ day/night conditions) and watered regularly with sterile water. Seedling trays were rearranged randomly every two days. Forty days after transplantation, plants were destructively harvested. The disease index for each plant was recorded based on a scale ranging from 0 to 4 [23]. Disease severity for each replicate seedling plate was calculated as described by: Disease severity $=[\Sigma$ (The number of diseased plants in the disease index category $x$ disease index category)/ (Total number of plants used in the experiment $\times$ highest disease index category) $] \times 100 \%[23,24]$. Simultaneously, we collected rhizosphere soil samples following an established protocol [4]. Briefly, two plants were randomly chosen from each replicate seedling tray to collect rhizosphere soils and further combined to yield one sample, 

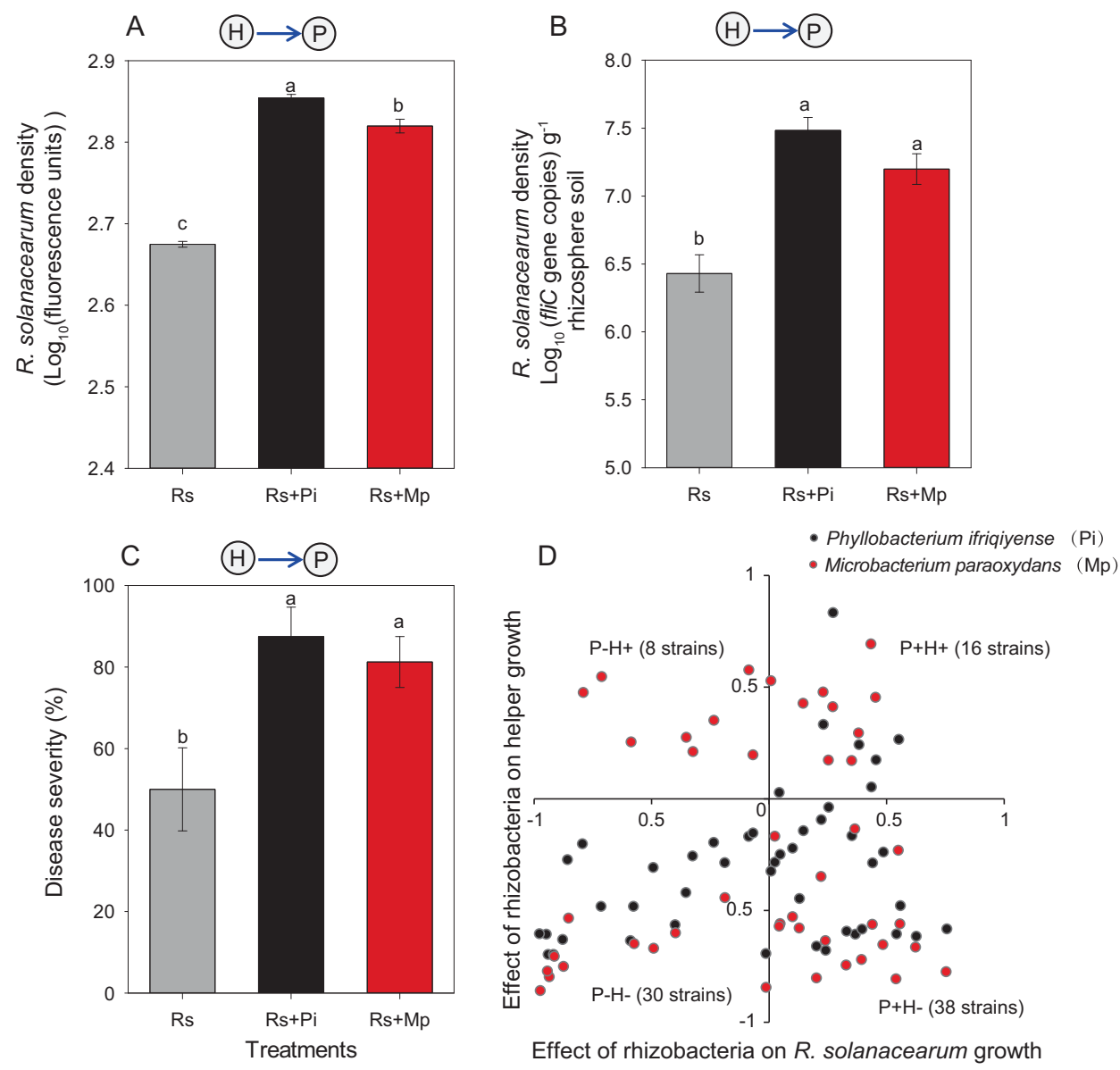

Fig. 3 Effect of helper strains on Ralstonia solanacearum growth and plant disease severity. Effects of the two helper strains Phyllobacterium ifriqiyense ( $\mathrm{Pi}$ ) and Microbacterium paraoxydans ( $\mathrm{Mp}$ ) on Ralstonia solanacearum (Rs) growth in vitro (A) and in vivo (B) and on plant disease severity $(\mathbf{C})$. Different letters indicate significant differences based on Tukey post hoc test. Error bars show \pm 1 SE $(n=3$ for in vitro, $n=4$ for in vivo). D Effects of 46 rhizobacterial strains on the growth of $R$. solanacearum and the two model helper strains in vitro. The $\mathrm{x}$-axis shows the direct effect of each rhizobacterial strain on $R$. solanacearum growth (data from the experiment in which $R$. solanacearum was grown in the presence of supernatant from each of the 46 rhizobacterial strains-the same data is presented on the $x$ axis of Fig. $4 \mathrm{~A}$ ). The $y$-axis shows the effect of each rhizobacterial strain on each of the two helper strains (data from the experiment in which each helper was grown in the presence of supernatant from each of the 46 rhizobacterial strains-the same data is presented on the $x$ axis of Fig. 4C). In (C), " -1 ", " 0 " and " 1 " on the $\mathrm{x}$-axis denote that $R$. solanacearum growth is completely inhibited, not influenced or increased $2 \times$ by supernatant from the rhizobacteria, respectively. Similarly, " -1 ", "0" and " 1 " on the $y$-axis denote the same growth effects with reference to growth of the helper strains. Black dots indicate results involving interactions with $\mathrm{Pi}$, and red dots indicate results involving interactions with $\mathrm{Mp}$.

resulting in a total of 112 rhizosphere soil samples for which $R$. solanacearum population densities were determined.

\section{Quantification of $R$. solanacearum at the end of the in vivo experiment}

We determined $R$. solanacearum densities using quantitative PCR (qPCR). DNA was extracted from rhizosphere soils using a Power Soil DNA isolation kit (Mo Bio Laboratories) following the manufacturer's protocol. DNA concentrations were determined by using a NanoDrop 1000 spectrophotometer (Thermo Scientific) and extracted DNA was used for $R$. solanacearum density measurements using specific primers (forward, 5'GAA CGC CAA CGG TGC GAA CT-3'; reverse, 5'-GGC GGC CTT CAG GGA GGT C-3) targeting the fliC gene, which encodes the $R$. solanacearum flagellum subunit [25]. The qPCR analyses were carried out with a StepOnePlus RealTime RCR Instrument using SYBR green fluorescent dye detection and three technical replicates as described previously [4].

\section{Statistical analyses}

To meet assumptions of normality and homogeneity of variance, $R$. solanacearum densities measured in vitro and in vivo were log10transformed. When comparing mean differences between treatments, we used analyses of variance (ANOVA) and the Tukey Test, where $p$ values lower than 0.05 were considered statistically significant. $R$. solanacearum densities were explained by two quantitative indices, the direct effect of rhizobacteria on $R$. solanacearum growth (the effect of rhizobacteria on $R$. solanacearum growth) and the indirect effect of rhizobacteria on $R$. solanacearum growth (the effect of rhizobacteria on helper strains' growth). Nonlinear regression analyses (Sigmoidal, Sigmoid, 3 Parameter) were used to analyze the relationship between the direct effect and pathogen density, as well as the relationship between indirect effects and pathogen density in the presence of helper strains in vitro. The relationships between them, and between direct/indirect effects and disease severity in the presence of helper strains in vivo, were analyzed using linear regressions. These analyses were carried out using the R 3.6.3 program (www.r-project.org) and Sigma Plot (V.12.5).

To further consider the growth inhibition of $R$. solanacearum, and disease suppression, we fitted a linear model to estimate the relative importance of direct effects versus indirect effects on the density of $R$. solanacearum both in vitro and in vivo, and on disease severity. This model considered the interaction scenario where rhizobacterial strains inhibited both the pathogen and its helpers (see the R script "Model" in the supplementary information). These analyses were performed in $\mathrm{R}$ version 3.6 .3 [26] in conjunction with the package car, readxl and dplyr, and tidyverse 1.2.1 [27]. Briefly, proportional effects were normalized using a folded cube root transformation as suggested in J.W. Tukey [28] and fitted using a linear model with direct effects, indirect effects, and an interaction between helper strains and indirect effects as fixed factors. Normality of 

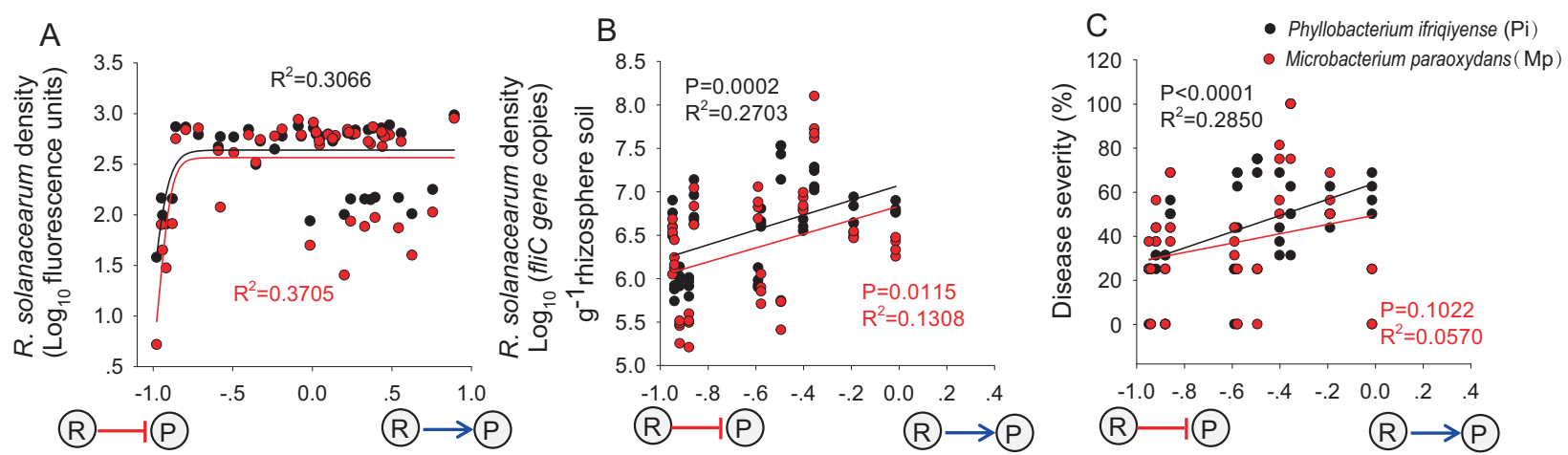

Direct effect (effect of rhizobacteria on $R$. solanacearum growth)
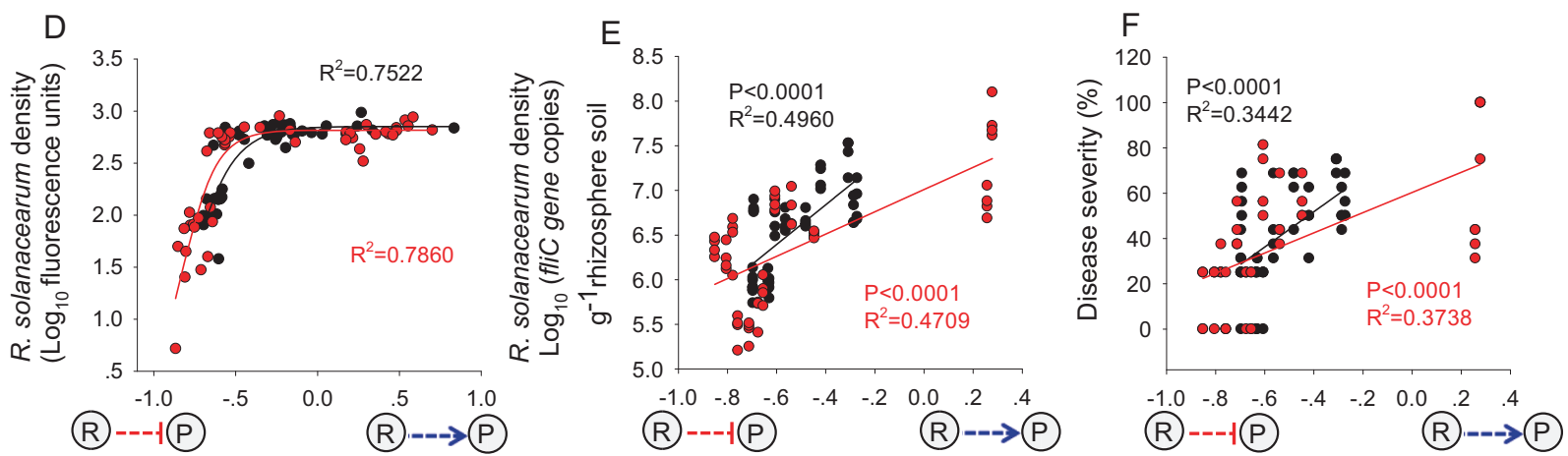

Indirect effect (effect of rhizobacteria on helper growth)

Fig. 4 The importance of direct versus indirect effects on Ralstonia solanacearum density and disease severity in the presence of helper strains. In the presence of helper Phyllobacterium ifriqiyense (Pi) or Microbacterium paraoxydans (Mp), respectively, the importance of direct effects on the density of $R$. solanacearum both $(\mathbf{A})$ in vitro and $(\mathbf{B})$ in vivo, and $(\mathbf{C})$ disease severity (the data on the $\mathrm{x}$ axis of $(\mathbf{A})$ are the same data which was presented on the $x$ axis of Fig. 3 C, the data on $x$ axis of $(\mathbf{B})$ and $(\mathbf{C})$ are part of the data on $x$ axis of $(\mathbf{A})$ ); the importance of indirect effects on the density of $R$. solanacearum both (D) in vitro and (E) in vivo, and (F) disease severity (the data on the $x$ axis of (D) are the same data which was presented on the $y$ axis of Fig. 3C, the data on $x$ axis of (E) and (F) are part of the data on $x$ axis of (D)). In all panels, " -1 ", " 0 " and " 1 " on the $\mathrm{x}$-axis denote that $R$. solanacearum growth $(\mathbf{A}, \mathbf{B}$, and $\mathbf{C})$ or helper growth $(\mathbf{D}, \mathbf{E}$, and $\mathbf{F})$ is completely inhibited, not influenced or increased $2 \times$ by supernatant from the rhizobacteria, respectively.
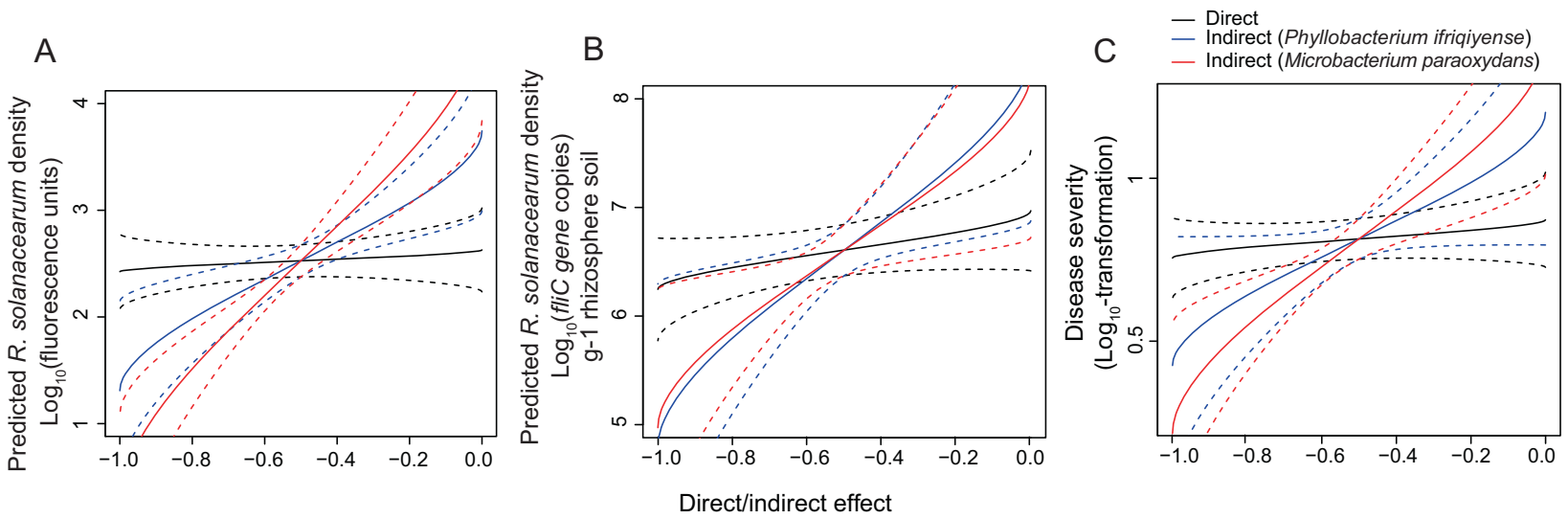

Fig. 5 The relative importance of direct versus indirect effects on Ralstonia solanacearum density and disease severity in the presence of helper strains. Relative importance of direct versus indirect effects on Ralstonia solanacearum density both in vitro (A) and in vivo (B), and disease severity $(\mathbf{C})$ in presence of helper strains on the interaction scenario where rhizobacterial strains inhibited both the pathogen and its helpers (quadrant " $\mathrm{H}^{-} \mathrm{P}^{-\prime}$ in Fig. $3 C$ ). This shows the predicted $R$. solanacearum densities and disease incidence for different values of the inhibition via pathogen (Direct) or helper (Indirect) as estimated from the statistical model (Table 1) which with direct effects, indirect effects, and an interaction between helper strains and indirect effects as fixed factors. For the Direct line, the indirect effect was set to zero, while for the indirect line, the direct effect was set to zero.

residuals was tested using the Shapiro-Wilk normality test and visual inspection of QQ-plots with standardized residuals. Type-II sum of squares were calculated using the ANOVA function from car 3.0-2 [29]. Subsequent visualization of the model outcome (results in Fig. 5) showed the predicted
R. solanacearum densities and disease severity for different values of the inhibition via pathogen (Direct) or helper (Indirect) as estimated from the statistical model. For the Direct effect line, the indirect effect is set to be zero, while for the Indirect effect line, the direct effect is set to be zero. 
Table 1. ANOVA table comparing the contribution of direct and indirect effects of the different tested bacterial isolates on the density of Ralstonia solanacearum in vitro and in vivo, as well as disease severity on the interaction scenario where rhizobacteria inhibited both the pathogen and its helpers (quadrant " $\mathrm{H}^{-} \mathrm{P}^{-\prime}$ in Fig. $3 \mathrm{C}$ ).

\begin{tabular}{|c|c|c|c|c|c|c|c|c|c|}
\hline & \multicolumn{3}{|c|}{$\begin{array}{l}\text { R. solanacearum density } \\
\text { in vitro }\end{array}$} & \multicolumn{3}{|c|}{$\begin{array}{l}\text { R. solanacearum density } \\
\text { in vivo }\end{array}$} & \multicolumn{3}{|c|}{ Disease severity } \\
\hline & $d f$ & $\boldsymbol{F}$ & $P$ & $d f$ & $\boldsymbol{F}$ & $P$ & $d f$ & $\boldsymbol{F}$ & $P$ \\
\hline Direct effect & 1 & 2.4521 & 0.1295 & 1 & 2.7504 & 0.1146 & 1 & 1.0440 & 0.3204 \\
\hline Indirect effect & 1 & 32.9556 & $4.818 \mathrm{e}-06$ & 1 & 11.5760 & 0.0032 & 1 & 14.3290 & 0.0014 \\
\hline Indirect effect: $\mathrm{Mp}$ vs $\mathrm{Pi}$ & 1 & 5.0717 & 0.0330 & 1 & 0.0376 & 0.8485 & 1 & 0.7262 & 0.4053 \\
\hline No. of residuals & 26 & & & 18 & & & 18 & & \\
\hline
\end{tabular}

\section{RESULTS}

Taxonomic characterization of inhibiting and helping strains of Ralstonia solanacearum from the tomato rhizosphere The 160 non-redundant isolates we examined were classified within four main phyla, with the following distribution: Proteobacteria $33.1 \%$, Firmicutes $25.0 \%$, Bacteroidetes $19.4 \%$ and Actinobacteria $22.5 \%$. This collection contained a total of 23 families and 48 genera (Fig. S3). A total of $26.9 \%$ of these isolated rhizobacteria were shown to inhibit pathogen growth in vitro, while $50.6 \%$ of them significantly stimulated pathogen growth. We refer to these two categories as pathogen inhibitors and helpers, respectively (Fig. 2A). Although both helpers and inhibitors were found within each represented phylum, there were clear phylum-level differences with respect to the relative proportion of inhibitors versus helpers (Fig. 2B). For instance, $42.5 \%$ of the isolates affiliated with the Firmicutes showed inhibition of $R$. solanacearum growth, while $49.1 \%$ of the Proteobacteria isolates, $51.6 \%$ of the Bacteroidetes isolates and $63.9 \%$ of the Actinobacteria isolates were found to act as helpers (Fig. 2C).

\section{Pairwise interactions between helper strains of $\boldsymbol{R}$. solanacearum and other rhizobacterial strains}

To examine direct versus indirect effects on pathogen growth, we first chose two model helper strains: Phyllobacterium ifriqiyense LM1 ( $\mathrm{Pi})$ and Microbacterium paraoxydans LM2 (Mp). The helper strain $\mathrm{Pi}$ increased $R$. solanacearum density by $51.2 \%$ in vitro (Fig. $3 \mathrm{~A}$ ), by $946.7 \%$ (from $10^{6.4}$ to $10^{7.4}$ ) when grown in vivo with tomato plants (Fig. 3B), and increased disease severity by $75 \%$ (Fig. 3C). Similarly, Mp increased $R$. solanacearum density by $39.7 \%$ in vitro (Fig. $3 \mathrm{~A}$ ), by $461.6 \%$ (from $10^{6.43}$ to $10^{7.20}$ ) in vivo (Fig. $3 \mathrm{~B}$ ), and increased disease severity by $62.5 \%$ (Fig. $3 \mathrm{C}$ ).

We then selected 46 rhizobacterial strains from the full rhizobacterial strain collection to represent a range of positive (50.0\%), negative (34.8\%) or neutral (15.2\%) effects on $R$. solanacearum growth (Fig. S4). We defined these interactions as the direct effect of rhizobacteria on $R$. solanacearum growth ( $\mathrm{x}$ axis of Figs. $3 C$ and $4 A, B, C)$. We tested the effects of the supernatant from each of these 46 rhizobacterial strains on each of the helper strains, $\mathrm{Mp}$ and $\mathrm{Pi}$. We found that $10.9 \%$ of the strains positively affected the growth of $\mathrm{Pi}$, while $82.6 \%$ reduced $\mathrm{Pi}$ growth and $6.5 \%$ had no significant effect (Fig. S4). Following a distinct but comparable pattern, Mp was positively affected by $37.0 \%$ of the tested isolates and negatively by $63.0 \%$ of them (Fig. S4). We defined these interactions as the indirect effects of rhizobacteria on $R$. solanacearum growth ( $y$ axis of Fig. $3 C$ and $x$ axis of Fig. 4D, E, F).

When considering the direct effect of each rhizobacterial strain with their indirect effects on the growth of $R$. solanacearum, four possible combinations were considered (Fig. 3C): (i) 8 strain combinations showed negative direct effects and positive indirect effects $\left(\mathrm{P}^{-} \mathrm{H}^{+}\right)$, (ii) 16 strain combinations showed positive direct effects and positive indirect effects $\left(\mathrm{P}^{+} \mathrm{H}^{+}\right)$, (iii) 30 strain combinations showed negative direct effects and negative indirect effects $\left(\mathrm{P}^{-} \mathrm{H}^{-}\right)$and (iv) 38 strain combinations showed positive direct effects and negative indirect effects $\left(\mathrm{P}^{+} \mathrm{H}^{-}\right)$. A large majority of strain combinations fell into two of these categories, with $32.6 \%$ being $\mathrm{P}^{-} \mathrm{H}^{-}$and $41.3 \%$ being $\mathrm{P}^{+} \mathrm{H}^{-}$, suggesting that indirect negative effects may be relevant to reducing the growth of $R$. solanacearum. Given this distribution and desire to examine pathways toward $R$. solanacearum inhibition, we focused subsequent modeling work (described in Fig. 5 and Table 1) on the " $\mathrm{P}^{-} \mathrm{H}^{-\prime}$ quadrant, to examine the relative importance of direct effects versus indirect effects on the density of $R$. solanacearum and plant disease severity.

\section{The importance of direct versus indirect effects on $R$. solanacearum density and plant disease severity in the presence of helper strains}

In the presence of the helper strain $\mathrm{Pi}$, the direct effects of the rhizobacteria explained a significant proportion of the variation in $R$. solanacearum density in vitro $\left(R^{2}=0.3066\right.$, black line in Fig. $\left.4 \mathrm{~A}\right)$ and in vivo $\left(R^{2}=0.2703, P=0.0002\right.$, black line in Fig. $\left.4 \mathrm{~B}\right)$, as well as the level of bacterial wilt disease severity observed $\left(R^{2}=0.2850\right.$, $P<0.0001$, black line in Fig. 4C). The indirect effects of the rhizobacteria explained a larger proportion of the observed variation in $R$. solanacearum density as compared to the direct effects for the in vitro assay $\left(R^{2}=0.7522\right.$, black line in Fig. 4D) and the in vivo assay $\left(R^{2}=0.4960, P<0.0001\right.$, black line in Fig. $\left.4 \mathrm{E}\right)$, as well as for the observed level of bacterial wilt disease incidence $\left(R^{2}=0.3442, P<0.0001\right.$, black line in Fig. 4F).

When in the presence of the helper strain $\mathrm{Mp}$, the direct effects on $R$. solanacearum density were again significant both in vitro $\left(R^{2}=\right.$ 0.3705 , red line in Fig. $4 A)$ and in vivo $\left(R^{2}=0.1308, P=0.0115\right.$, red line in Fig. 4B), but the direct effects did not correlate significantly with bacterial wilt disease severity (red line in Fig. 4C). In the presence of this helper strain, $R$. solanacearum density was again correlated with indirect effects in vitro $\left(R^{2}=0.7860\right.$, red line in Fig. 4D) and in vivo $\left(R^{2}=0.4709, P<0.0001\right.$, red line in Fig. 4E), as well as with the level of bacterial wilt disease severity $\left(R^{2}=0.3738\right.$, $P<0.0001$, red line in Fig. 4F).

In the presence of either helper, $\mathrm{Pi}$ or $\mathrm{Mp}$, the indirect effects explained more of the total variation in $R$. solanacearum density and disease severity than the direct effects, with the regression for indirect effects yielding higher $r$-square values than that for direct effects (Fig. 4A-F). Together, these results demonstrate that inhibition of pathogen helper strains has the potential to limit the growth of $R$. solanacearum both in vitro and in vivo, and to reduce of bacterial wilt disease severity. To gain further insight into the potential prevalence of such a mechanism, we considered this strategy using a modeling approach targeting the relative importance of direct versus indirect effects on pathogen growth and disease severity.

\section{Relative contribution of direct versus indirect effects on $R$. solanacearum density and disease severity in the presence of helper strains}

To further consider growth inhibition of $R$. solanacearum and decrease in bacterial wilt disease severity, we focused our 
modeling approach on the interaction scenarios where rhizobacterial strains inhibited both the pathogen and its helpers (quadrant " $\mathrm{H}^{-} \mathrm{P}^{-}$" in Fig. $3 \mathrm{C}$ ). We constructed a model to predict the direct effects versus indirect effects on the density of $R$. solanacearum both in vitro and in vivo, as well as on disease severity. We found that indirect effects provided far better prediction of $R$. solanacearum density in vitro (Fig. 5A and Table 1) and in vivo (Fig. $5 \mathrm{~B}$ and Table 1 ) and bacterial wilt disease severity (Fig. 5C and Table 1), as compared to direct effects on the pathogen. Together, these results suggest that indirect effects of rhizobacteria on the helpers' growth predicted pathogen density better than direct effects on the pathogen itself.

\section{DISCUSSION}

In this study, we evaluated the prevalence of pathogen-helper bacterial strains in the tomato rhizosphere microbiome as well as the potential to target such helpers for microbiome management strategies aiming to reduce pathogen growth. As a model pathogen, we used Ralstonia solanacearum, a widespread and problematic phytopathogenic bacterium that causes wilt diseases on tomatoes and more than 200 economically important crops and ornamentals [30]. Combining in vitro and in vivo approaches, we compared the influence of the direct (i.e., on $R$. solanacearum growth directly) vs. the indirect (i.e. on the growth of $R$. solanacearum helper strains) effects of tomato-associated rhizobacteria on the growth of the pathogen as well as subsequent development of disease symptoms. Overall, indirect effects, i.e. inhibition of helper strains, were the major determinants of pathogen suppression as compared to direct impacts on the pathogen itself. To our knowledge, this represents the first demonstration of such an indirect strategy for the potential suppression of soil-borne plant disease.

The isolated rhizobacteria in this study belonged to four major phyla (Proteobacteria, Firmicutes, Bacteroidetes and Actinobacteria), which are collectively presumed to be copiotrophs [31,32] and are known to be dominant phyla found in the rhizosphere [33]. We found facilitation to be widespread, with half of the tested isolates $(50.6 \%)$ promoting pathogen growth using a supernatant assay. This result adds to the recent insights that many microorganisms may act as helpers of pathogens in the rhizosphere [11]. Indeed, different bacterial strains affiliated with Bacillus and Microbacterium were previously shown to have a modest but significant stimulatory effect on the growth of $R$. solanacearum and a promotion of disease development [11]. Also, some fungi affiliated with Ascomycetes, Basidiomycetes and Zygomycetes have been shown to facilitate pathogen entry into tomato roots by producing chlamydospores that can host $R$. solanacearum cells [34]. Moreover, one Pseudomonas phylotype was found to exacerbate disease symptoms in tomato plants by establishing commensal interactions with an oomycete pathogen to increase its access to plant nutrients [35]. Interestingly, most of the helpers in our study belonged to the Proteobacteria (49.1\%) and Actinobacteria (63.9\%), two phylogenetic groups that are often highlighted for containing bacteria that are effective at suppressing pathogen growth $[36,37]$. Our results thus call for a rethinking of the interactions that shape the microbiome, with the realization that facilitation is widespread and important. However, it should be noted that the rhizobacterial collection we utilized in this study clearly does not provide a full taxonomic inventory of the rhizosphere microbiome. For instance, the medium we used most likely selected for more copiotrophic strains from the full soil microbiome. Such copiotrophs might have different effects on pathogen growth as compared to more oligotrophic bacteria, because they typically have higher growth rates and lower substrate affinities [38].

Several mechanisms have been put forth to explain mutualism or commensalism among bacteria, mainly as related to the benefits gained from the use of metabolites processed by another member of the community [39]. For instance, peptidoglycan produced by Bacillus cereus may promote the growth of several bacterial strains affiliated with the Cytophaga-Flavobacterium group [40]. Siderophores produced by microorganisms can also be accepted as public goods by other bacteria with siderophore protein receptors to obtain limited iron in the environment to maintain growth and metabolism, hence increasing population biomass [41]. Although beyond the scope of the current study, the promoting mechanisms of the helper strains towards $R$. solanacearum are most likely related to certain metabolites, as promotion was also observed using supernatant assays (Figs. $2 \mathrm{~A}$ and $3 \mathrm{~A}$ ).

In general, the indirect effects of the rhizobacteria we studied were the best predictors of $R$. solanacearum density and the realized level of plant disease severity (Fig. 4D, E, F). It is noteworthy that the level of variation explained by indirect effects was higher in our in vitro assays (75\% and $79 \%$, Fig. 4D) as compared to our in vivo experiments (less than $50 \%$, Fig. 4E, F). This difference might be explained by the more open nature of the plant rhizosphere as compared to the in vitro setting. Variation in environmental aspects such as soil structure and the resident microbiome also could contribute to a great level of variation in realized pathogen density. Alternatively, microbial impacts on plant immunity might also impact the level of plant disease observed $[42,43]$. For instance, several bacterial secondary metabolites involved in pathogen suppression may also impact plant immunity: for example, 2,4diacetylphloroglucinol (DAPG) produced by fluorescent Pseudomonas spp. [44] or lipopeptide surfactins produced by Bacillus subtilis [45] have such a dual function.

The rhizobacterial strains used in this study exhibited a wide range of effects on the pathogen and its bacterial helper strains. Many of them inhibited both $R$. solanacearum as well as its helpers. Our model on the interaction scenarios where rhizobacterial strains inhibited both the pathogen and its helpers (quadrant " $\mathrm{H}^{-} \mathrm{P}^{-\prime}$ in Fig. $3 \mathrm{C}$ ) showed that inhibition of the helper strains was a more effective path toward $R$. solanacearum reduction than direct inhibition effects on the pathogen itself. Even if a biocontrol agent is active against $R$. solanacearum $[4,18]$, its efficiency in reality may be more due to its interaction with indigenous helpers. We therefore propose that strategies for integrated biological control of the pathogen need to be reconsidered to incorporate indirect effects on pathogen helpers to provide more ecological solutions to combat soil-borne pathogens. Although the underlying mechanisms of helper inhibition still need to be unraveled and our communities here were far less diverse and far simpler than natural communities, our findings contribute to our knowledge of rhizobacteria-pathogen interactions and provide a new potential strategy for efficient and sustainable biological control of soil-borne pathogens.

\section{REFERENCES}

1. Nicolopoulou-Stamati P, Maipas S, Kotampasi C, Stamatis P, Hens L. Chemical pesticides and human health: The urgent need for a new concept in agriculture. Front Public Health. 2016;4:148.

2. Kwak MJ, Kong HG, Choi K, Kwon SK, Song JY, Lee J, et al. Rhizosphere microbiome structure alters to enable wilt resistance in tomato. Nat Biotechnol. 2018;36:1100-9.

3. Compant S, Samad A, Faist H, Sessitsch A. A review on the plant microbiome: ecology, functions, and emerging trends in microbial application. J Adv Res. 2019;19:29-37.

4. Hu J, Wei Z, Friman V-P, Gu S-h, Wang X-f, Eisenhauer N, et al. Probiotic diversity enhances rhizosphere microbiome function and plant disease suppression. mBio. 2016;7:e01790-16.

5. Berendsen RL, Pieterse CMJ, Bakker PAHM. The rhizosphere microbiome and plant health. Trends Plant Sci. 2012;17:478-86.

6. Mazzola M, Freilich S. Prospects for biological soilborne disease control: application of indigenous versus synthetic microbiomes. Phytopathology. 2017;107:256-63.

7. Wei Z, Huang JF, Hu J, Gu YA, Yang CL, Mei XL, et al. Altering transplantation time to avoid periods of high temperature can efficiently reduce bacterial wilt disease incidence with tomato. PloS One. 2015;10:e0139313. 
8. Wei Z, Yang XM, Yin SX, Shen QR, Ran W, Xu YC. Efficacy of bacillus-fortified organic fertiliser in controlling bacterial wilt of tomato in the field. Appl Soil Ecol. 2011;48:152-9.

9. Li M, Wei Z, Wang JN, Jousset A, Friman VP, Xu YC, et al. Facilitation promotes invasions in plant-associated microbial communities. Ecol Lett. 2019;22:149-58.

10. Hu Q, Tan L, Gu S, Xiao Y, Xiong X, Zeng WA, et al. Network analysis infers the wilt pathogen invasion associated with non-detrimental bacteria. NPJ Biofilms Microbiomes. 2020;6:8.

11. Gu S, Wei Z, Shao Z, Friman VP, Cao K, Yang T, et al. Competition for iron drives phytopathogen control by natural rhizosphere microbiomes. Nat Microbiol. 2020;5:1002-10.

12. Pacheco AR, Moel M, Segre D. Costless metabolic secretions as drivers of interspecies interactions in microbial ecosystems. Nat Commun. 2019;10:103.

13. Kramer J, Özkaya Ö, Kümmerli R. Bacterial siderophores in community and host interactions. Nat Rev Microbiol. 2020;18:152-63.

14. Gao $\mathrm{CH}$, Zhang $M, \mathrm{Wu} Y$, Huang Q, Cai P. Divergent influence to a pathogen invader by resident bacteria with different social interactions. Microb Ecol. 2019;77:76-86.

15. Hayward AC. Biology and epidemiology of bacterial wilt caused by Pseudomonas-solanacearum. Annu Rev Phytopathol. 1991;29:65-87.

16. Jiang G, Wei Z, Xu J, Chen H, Zhang Y, She X, et al. Bacterial wilt in China: history, current status, and future perspectives. Front Plant Sci. 2017;8:1549.

17. Heuer $H$, Krsek M, Baker $P$, Smalla K, Wellington EM. Analysis of actinomycete communities by specific amplification of genes encoding $16 \mathrm{~S}$ rRNA and gelelectrophoretic separation in denaturing gradients. Appl Environ Microbiol. 1997;63:3233-41.

18. Wei Z, Yang T, Friman VP, Xu Y, Shen Q, Jousset A. Trophic network architecture of root-associated bacterial communities determines pathogen invasion and plant health. Nat Commun. 2015;6:8413.

19. Altschul SF, Madden TL, Schäffer AA, Zhang J, Zhang Z, Miller W, et al. Gapped BLAST and PSI-BLAST: A new generation of protein database search programs. Nucleic Acids Res. 1997;25:3389-402.

20. Edgar RC. MUSCLE: Multiple sequence alignment with high accuracy and high throughput. Nucleic Acids Res. 2004;32:1792-7.

21. Kumar S, Stecher G, Li M, Knyaz C, Tamura K. MEGA X: molecular evolutionary genetics analysis across computing platforms. Mol Biol Evol. 2018;35:1547-9.

22. Wei Z, Huang J, Tan S, Mei X, Shen Q, Xu Y. The congeneric strain Ralstonia pickettii QL-A6 of Ralstonia solanacearum as an effective biocontrol agent for bacterial wilt of tomato. Biol Control. 2013;65:278-85.

23. Tans-Kersten J, Brown D, Allen C. Swimming motility, a virulence trait of Ralstonia solanacearum, is regulated by FlhDC and the plant host environment. Mol Plantmicrobe Interactions. 2004;17:686-95.

24. Wang X, Wei Z, Li M, Wang X, Shan A, Mei X, et al. Parasites and competitors suppress bacterial pathogen synergistically due to evolutionary trade-offs. Evolution. 2017;71:733-46.

25. Schönfeld J, Heuer H, Van Elsas JD, Smalla K. Specific and sensitive detection of Ralstonia solanacearum in soil on the basis of PCR amplification of fliC fragments. Appl Environ Microbiol. 2003;69:7248-56.

26. Team RC. R: A language and environment for statistical computing. 2013.

27. Wickham $\mathrm{H}$. Tidyverse: Easily install and load the 'Tidyverse'. R package version 1.2. 1. R Core Team: Vienna, Austria. 2017.

28. Tukey JW Exploratory data analysis: Reading, Mass.; 1977

29. Fox J, Weisberg S, Adler D, Bates D, Baud-Bovy G, Ellison S, et al. Package 'car'. Vienna: R Foundation for Statistical Computing. 2012

30. Álvarez B, Elena GBiosca, López MM. On the life of Ralstonia solanacearum, a destructive bacterial plant pathogen. Appl Microbiol Microb Biotechnol. 2010;1:267-79.

31. Schostag $M$, Priemé $A$, Jacquiod $S$, Russel J, Ekelund $F$, Jacobsen CS. Bacterial and protozoan dynamics upon thawing and freezing of an active layer permafrost soil. ISME J. 2019;13:1345-59.

32. Fierer N, Bradford MA, Jackson RB. Toward an ecological classification of soil bacteria. Ecology. 2007;88:1354-64.

33. Lagos L, Maruyama F, Nannipieri P, Mora M, Ogram A, Jorquera M. Current overview on the study of bacteria in the rhizosphere by modern molecular techniques: a mini-review. J Soil Sci Plant Nutr. 2015;15:504-23.

34. Spraker JE, Sanchez LM, Lowe TM, Dorrestein PC, Keller NP. Ralstonia solanacearum lipopeptide induces chlamydospore development in fungi and facilitates bacterial entry into fungal tissues. Isme J. 2016;10:2317-30.

35. Larousse M, Rancurel C, Syska C, Palero F, Etienne C, Industri B, et al. Tomato root microbiota and Phytophthora parasitica-associated disease. Microbiome. 2017;5:56.

36. Cha JY, Han S, Hong HJ, Cho H, Kim D, Kwon Y, et al. Microbial and biochemical basis of a Fusarium wilt-suppressive soil. Isme J. 2016;10:119-29.

37. Mendes R, Kruijt M, de Bruijn I, Dekkers E, van der Voort M, Schneider JHM, et al. Deciphering the rhizosphere microbiome for disease-suppressive bacteria. Science. 2011;332:1097-100.
38. Kurm V, Van Der Putten WH, De Boer W, Naus-Wiezer S, Hol WG. Low abundant soil bacteria can be metabolically versatile and fast growing. Ecology. 2017:98:555-64.

39. Grosskopf T, Soyer OS. Synthetic microbial communities. Curr Opin Microbiol. 2014;18:72-7.

40. Peterson SB, Dunn AK, Klimowicz AK, Handelsman J. Peptidoglycan from Bacillus cereus mediates commensalism with rhizosphere bacteria from the CytophagaFlavobacterium group. Appl Environ Microbiol. 2006;72:5421-7.

41. Hibbing ME, Fuqua $C$, Parsek MR, Peterson SB. Bacterial competition: surviving and thriving in the microbial jungle. Nat Rev Microbiol. 2010;8:15-25.

42. Liu H, Brettell LE, Qiu Z, Singh BK. Microbiome-mediated stress resistance in plants. Trends Plant Sci. 2020;25:733-43.

43. Berendsen RL, Vismans G, Yu K, Song Y, de Jonge R, Burgman WP, et al. Diseaseinduced assemblage of a plant-beneficial bacterial consortium. Isme J. 2018;12:1496-507.

44. Mavrodi DV, Mavrodi OV, Parejko JA, Weller DM, Thomashow LS. The role of 2, 4diacetylphloroglucinol-and phenazine-1-carboxylic acid-producing Pseudomonas spp. in natural protection of wheat from soilborne pathogens. Bacteria in Agrobiology: Plant Nutrient Management: Springer; 2011. p. 267-83.

45. Jourdan E, Henry G, Duby F, Dommes J, Barthelemy J-P, Thonart P, et al. Insights into the defense-related events occurring in plant cells following perception of surfactintype lipopeptide from Bacillus subtilis. Mol Plant-Microbe Interact. 2009;22:456-68.

\section{ACKNOWLEDGEMENTS}

This research was financially supported by the National Key Research and Development Program of China (SQ2021YFD1900024), National Natural Science Foundation of China $(31972504,42090060,41922053$, and 42007038), the Fundamental Research Funds for the Central Universities (KY2201719, KYT201802, KYXK202010, KJQN202116-KJQN202117), the Natural Science Foundation of Jiangsu Province (BK20190518, BK20180527 and BK20200533), and technically supported by the Bioinformatics Center of Nanjing Agricultural University. ML was supported by Chinese Scholarship Council (CSC).

\section{AUTHOR CONTRIBUTIONS}

$\mathrm{ML}, \mathrm{ZW}, \mathrm{YX}, \mathrm{QS}, \mathrm{TP}, \mathrm{AJ}$, and GK designed research; ML, YY, JW, and GH performed research; $M L, Z W, H W$, and JK analyzed data; $M L, Z W, A J, T P$, and GK wrote the manuscript; all authors contributed to the final draft.

\section{COMPETING INTERESTS}

The authors declare no competing interests.

\section{ADDITIONAL INFORMATION}

Supplementary information The online version contains supplementary material available at https://doi.org/10.1038/s41396-021-01126-2.

Correspondence and requests for materials should be addressed to Zhong Wei.

Reprints and permission information is available at http://www.nature.com/ reprints

Publisher's note Springer Nature remains neutral with regard to jurisdictional claims in published maps and institutional affiliations.

\footnotetext{
Open Access This article is licensed under a Creative Commons Attribution 4.0 International License, which permits use, sharing, adaptation, distribution and reproduction in any medium or format, as long as you give appropriate credit to the original author(s) and the source, provide a link to the Creative Commons licence, and indicate if changes were made. The images or other third party material in this article are included in the article's Creative Commons licence, unless indicated otherwise in a credit line to the material. If material is not included in the article's Creative Commons licence and your intended use is not permitted by statutory regulation or exceeds the permitted use, you will need to obtain permission directly from the copyright holder. To view a copy of this licence, visit http://creativecommons. org/licenses/by/4.0/.
}

(c) The Author(s) 2021 